\title{
A 3-Years Pneumonia Incidence in Burn Cases with Inhalation Injury at the Burn Center of Dr. Soetomo General Hospital Surabaya in 2015- 2018
}

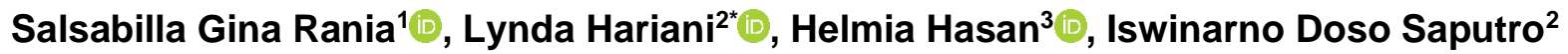

${ }^{1}$ Faculty of Medicine, Universitas Airlangga, Surabaya, Indonesia.

2Department of Plastic, Reconstructive, and Aesthetic Surgery, Faculty of Medicine, Universitas Airlangga/Dr. Soetomo General Hospital, Surabaya, Indonesia.

${ }^{3}$ Department of Pulmonology and Respiratory Medicine, Universitas Airlangga/Dr. Soetomo General Hospital, Surabaya, Indonesia.

\section{A B S T R A C T}

Introduction: Inhalation injury is one of burns impact. Airway burns due to inhalation injury is a non-specific term which refer to all respiratory tract injuries occurred due to irritative chemicals, including heat and smoke during inspiration. Inhalation injury increases the risk of death in burns. Pneumonia is one of burns-related inhalation injury complications.

Methods: This was a descriptive retrospective study aiming to determine the incidence of pneumonia in burn patients with inhalation injury using secondary data at Burn Center Dr. Soetomo General Hospital Surabaya in the period of January 2015 - December 2018.

Results: There were 5 cases of pneumonia in 14 burn cases with inhalation injury (35.71\%). Respectively, 2 and 3 cases were found in 2017 and 2018. There were 2 female $(40 \%)$ and 3 male $(60 \%)$ patients, with age varied within $28-73$ years old. The burn area of burn patients with inhalation injury and pneumonia were found by $15 \%$, $20 \%, 24 \%, 32 \%$ and $71 \%$, or within the classification of $11-20 \%$ burn area, and most complication found was hypoalbuminemia, as much as 3 cases $(60 \%)$.

Conclusion: Most pneumonia in burn cases with inhalation injury was occurred in 2018 , dominated by male patients. The age of the patient were ranging from early adulthood to elderly. Most burns were in the range of $11-20 \%$ burn area with the most complication found was hypoalbuminemia.

\footnotetext{
*Correspondence: lyndaagus@gmail.com

JUXTA: Jurnal IImiah Mahasiswa Kedokteran Universitas Airlangga p-ISSN: 1907-3623; e-ISSN: 2684-9453

DOI: 10.20473/juxta.V13I12022.27-30

Open access under Creative Commons Attribution-ShareAlike 4.0 International License (CC-BY-SA)
}

\section{ARTICLE INFO}

Article history:

Received 10 October 2021

Received in revised form 14

December 2021

Accepted 28 December 2021

Available online 5 January 2022

\section{Keywords:}

Burns,

Human \& health, Inhalation injury, Pneumonia. 


\section{Introduction}

Burns are a global public health problem due to its high mortality and morbidity rate, especially in middle to lower income countries that accounts for more than 95\% burns mortality. One of burns impact is inhalation injury. Airway burns due to inhalation injury are a non-specific term which refer to respiratory tract injuries due to irritative chemicals, including heat and smoke during inspiration. There may be local thermal exposure due to heat exchange or exposure to combustion byproducts. ${ }^{1}$ Smoke inhalation injury is a major determinant of mortality and morbidity in burns victims. This is a complex injuries which initially affects the airway, but shortly can become a life-threatening systemic disturbance that affects every organ in the body. ${ }^{2}$ Related to inhalation injury, infection is a major cause of morbidity and mortality in burn patients with inhalation injury and pneumonia which occurs in more than $80 \%$ of patients. Almost half of burn patients with bacterial infections mortality were caused by pneumonia. ${ }^{3}$

In 2014, World Health Organization (WHO) ${ }^{4}$ estimated that there were 265,000 deaths occurring each year worldwide due to burns. In India, more than one million people suffer from moderate to severe burns each year. In Bangladesh, Colombia, Egypt and Pakistan, 17\% of children with burns suffer from temporary disabilities and $18 \%$ suffer from permanent disabilities. According to American Burn Association (2016), ${ }^{5}$ in the United States there were 486,000 cases of burns that receive medical treatment with 40,000 of the patients must be hospitalized and 3,240 deaths occur annually due to burns. The prevalence of burns in Indonesia in 2013 was $0.7 \%$ and has decreased by $1.5 \%$ compared to 2008 (2.2\%). Inhalation injury increases the risk of death in burns and reaches a mortality rate of $30 \%$ in children. More than $50 \%$ of burns associated with inhalation injury with a mortality of $73 \%{ }^{6}$ The incidence of pneumonia worldwide is around 15\%$20 \%{ }^{7}$ In China, the average age of burn patients with pneumonia is 41.9 years with the male-to-female ratio of 1 : 1.8 In 2013 , pneumonia occurs in $4.5 \%$ burn patients in Indonesia. ${ }^{9}$ Pneumonia is the top 10 inpatient diseases in hospitals, with a prevalence in male and female as much as $53.95 \%$ and $46.05 \%$ respectively. Pneumonia has a high crude fatality rate (CFR), 7.6\% according to Indonesian Lung Doctors Association in 2014. ${ }^{10}$

This study aimed to determine the incidence of pneumonia in burns patients with inhalation injury. The mortality and morbidity rates in burns with inhalation injury and pneumonia complication are still increasing which raised interest in conducting this study. More than half of burn patients are in need of ventilator due to pneumonia. ${ }^{11}$ The incidence of pneumonia in burn patients with inhalation injury at Burn Center Dr. Soetomo General Hospital Surabaya has never been studied and analyzed. Research needs to be done to establish strategies to prevent mortality and morbidity in burn patients.

The aim of this study was to determine the incidence of pneumonia in burn cases with inhalation injury at the
Burn Center of Dr. Soetomo General Hospital Surabaya in 2015-2018 based on year, sex, age, complications, and burn area. Hopefully this study could provide data for further analysis and be an informational source regarding pneumonia cases in burn patients with inhalation injury for future management precautions. Mortality and morbidity rates hopefully could be reduced.

\section{Methods}

This was a descriptive retrospective study aiming to determine the incidence of pneumonia in burn patients with inhalation injury using secondary data at Burn Center Dr. Soetomo General Hospital Surabaya in the period $f$ January 2015 - December 2018.

The study population were burn patients with inhalation injury at Burn Center Dr. Soetomo General Hospital Surabaya in the period of January 2015 . December 2018. The sampling method used were total sampling for patients who met the inclusion criteria. Samples with incomplete data record were excluded.

Annual incidence, gender, and age were examined to observe complications, burn area, and pneumonia in burn patients. Variables were measured in inpatient facilities, processed and analyzed using Microsoft Excel, and represented through tables and diagrams or graphs.

\section{Results}

Table 1. The incidence of pneumonia in burn patients with inhalation injury

\begin{tabular}{ccc}
\hline Year & Frequency (n) & Percentage (\%) \\
\hline Burn cases & 3 & $21.43 \%$ \\
2015 & 1 & $7.14 \%$ \\
2016 & 4 & $28.58 \%$ \\
2017 & 6 & $42.85 \%$ \\
2018 & 14 & $100 \%$ \\
Total & 0 & $0 \%$ \\
Pneumonia cases in burn patients with inhalation injury \\
2015 & 0 & $0 \%$ \\
2016 & 2 & $40 \%$ \\
2017 & 3 & $60 \%$ \\
2018 & 5 & $100 \%$ \\
Total &
\end{tabular}

The Incidence of Burns with Inhalation Injury

Burn cases with inhalation injury were most occurred in 2018. The incidence rate from 2015 to 2016 decreased by 2 cases, then rapidly increased in 2017 and 2018, as much as 4 and 6 cases respectively.

\section{The Incidence of Pneumonia in Burn Patients with Inhalation Injury}

Pneumonia cases was occurred in 5 burn patients (35.71\%) with inhalation injury. Pneumonia most occurred in 2018 and no cases were found in 2015 and 2016 . Respectively, there were 2 and 3 pneumonia cases in 2017 and 2018. 


\section{Gender Distribution}

Most patients who experienced pneumonia in burns with inhalation injury were male, as much as 3 patients $(60 \%)$, with a male-to female ratio of $1.5: 1$.

\section{Age Distribution}

Most pneumonia cases in burn patients with inhalation injury were found in the age group of $46-55$ years old, as much as 2 patients (40\%), then followed by $26-35$ years old, 36-45 years old, and above 65 years old with 1 patient each. There were no pneumonia cases in other age category of burn patients with inhalation injury.

\section{Complication Distribution}

Most complication of pneumonia which occurred in burn patients with inhalation injury was hypoalbuminemia, as much as 3 patients $(60 \%)$, followed by anemia and sepsis with 2 patients each, and thrombocytopenia with 1 patient.

\section{Burn Area Distribution}

Most burn area category occurred in pneumonia cases of burn patients with inhalation injury was $11-20 \%$, as much as 2 patients (40\%), followed by $21-30 \%, 31-40 \%$ and $71-$ $80 \%$ with 1 patient each. No pneumonia cases were found in other burn area categories.

Table 2. Characteristics of pneumonia in burn patients with inhalation injury

\begin{tabular}{|c|c|c|}
\hline Characteristics & Frequency (n) & Percentage (\%) \\
\hline \multicolumn{3}{|l|}{ Gender } \\
\hline Male & 3 & $60 \%$ \\
\hline Female & 2 & $40 \%$ \\
\hline Total & 5 & $100 \%$ \\
\hline \multicolumn{3}{|l|}{ Age (years old) } \\
\hline $0-5$ & 0 & $0 \%$ \\
\hline $6-11$ & 0 & $0 \%$ \\
\hline $12-16$ & 0 & $0 \%$ \\
\hline $17-25$ & 0 & $0 \%$ \\
\hline $26-35$ & 1 & $20 \%$ \\
\hline $36-45$ & 1 & $20 \%$ \\
\hline $46-55$ & 2 & $40 \%$ \\
\hline $56-65$ & 0 & $0 \%$ \\
\hline$>65$ & 1 & $20 \%$ \\
\hline Total & 5 & $100 \%$ \\
\hline \multicolumn{3}{|l|}{ Complication } \\
\hline Hypoalbuminemia & 3 & $60 \%$ \\
\hline Anemia & 2 & $40 \%$ \\
\hline Sepsis & 2 & $40 \%$ \\
\hline Thrombocytopenia & 1 & $20 \%$ \\
\hline Total & 8 & $100 \%$ \\
\hline \multicolumn{3}{|l|}{ Burn Area } \\
\hline $0 \%-10 \%$ & 0 & $0 \%$ \\
\hline $11 \%-20 \%$ & 2 & $40 \%$ \\
\hline $21 \%-30 \%$ & 1 & $20 \%$ \\
\hline $31 \%-40 \%$ & 1 & $20 \%$ \\
\hline $41 \%-50 \%$ & 0 & $0 \%$ \\
\hline $51 \%-60 \%$ & 0 & $0 \%$ \\
\hline $61 \%-70 \%$ & 0 & $0 \%$ \\
\hline $71 \%-80 \%$ & 1 & $20 \%$ \\
\hline $81 \%-90 \%$ & 0 & $0 \%$ \\
\hline $91 \%-100 \%$ & 0 & $0 \%$ \\
\hline Total & 5 & $100 \%$ \\
\hline
\end{tabular}

\section{Discussion}

The results of this study showed that the incidence of pneumonia in burn patients with inhalation injury was 5 cases, or $35.71 \%$ of total of burn cases with inhalation injury. Pneumonia in burns patients with inhalation injury increased from 2 to 3 cases respectively in 2017 and 2018 .

Different results showed by Li, et al., ${ }^{12}$ with a significant reduction over a 5-year period in the number of patients from January 2011 to December 2015. These differences could possibly be caused by differences in pathogens that cause pneumonia in Surabaya, comorbid factors, and individual antibiotic responses, as well as the increasing number of secondary hospitals in Indonesia that provide decent facilities for treatment of burns which caused a decreased number of referral to Dr. Soetomo General Hospital Surabaya as a primary referral hospital.

Pneumonia in burns with inhalation injury occurred more in male than female patients in $3(60 \%)$ and $2(40 \%)$ cases respectively.

Chan, et al. ${ }^{8}$ pointed out similar results with increased incidence of pneumonia in male patients. More frequent cases in men may be due to work-related exposure which is more excessive in men who are working actively with jobs with higher risk than women. Men also tend to be less aware in doing works than women, hence work-related accidents, including burns, tend to be more frequent in men. ${ }^{8}$

All cases of pneumonia in burns with inhalation injury occurred in the range of early adult (26-35 years old) to elderly ( $>65$ years old) with most cases occurred in the age group of 46-55 years old. Chan, et al. ${ }^{8}$ pointed out that the incidence of pneumonia in burn patients increased in patients above 65 years old. The statement is almost in accordance with this study which found patients aged 73 years old. Most occurred complication was hypoalbuminemia, as much as 3 cases (60\%). The results in this study are similar to Soeselo ${ }^{13}$ at Atmajaya Hospital, with the most occurred complication was hypoalbuminemia.

Inflammatory conditions, such as burns, tend to cause hypoalbuminemia as a compensation of the increased release of serum albumin and other plasma substances into the plasma and cells. In a long-standing conditions, plasma volume can be normal, but relatively increased due to reduced red blood cells and an increase in fat-free mass volume. Fat-free mass is the largest albumin distribution volume leading to hypoalbuminemia, according to Soeters, et al. ${ }^{14}$

Damayanti ${ }^{15}$ stated that there was a significant relationship between albumin levels with community acquired pneumonia (CAP) in patient admission to the hospital. The lower the albumin level, the more severe the CAP.

The burn area in pneumonia patients of burns with inhalation injury varied, as much as $15 \%, 24 \%, 32 \%, 71 \%$ and $20 \%$ respectively, with the most occurence in the burn area category of $11-20 \%$. These results are in accordance 
with research conducted by Agbenorku, et al., ${ }^{12}$ which found that the most burn area category of burn patients with inhalation injury in Ghana occurred in the range of $11-20 \%$, as much as 18 of 59 patients (30.51\%).

Burns also increase the incidence of pneumonia rather than non-burn trauma. Burns aggravate damage to the respiratory system and increase mortality. Extensive burn area can cause pneumonia in hospitalized patients. Obtained from Chan, et al., 827 of 56 patients who had severe burns also had pneumonia.

An increase in burn area is related to a high incidence of pneumonia, because burns activate the complement cascade and induce intrapulmonary leukocyte aggregation and release ROS, which cause lung damage and further respiratory distress to patients with inhalation injury. This pathophysiological response is also associated with immunosuppression, according to Liodaki. ${ }^{11}$ In this study, the burn area of the patients were relatively limited. It could be caused by unfulfilled criteria of burns for most of the lesion, including facial burn area, a confined space burns, and accompanied by soot.

\section{Conclusion}

Most pneumonia cases in burn patiens with inhalation injury was occurred in 2018. The majority of patients with pneumonia was male and in the age group of 46-55 years old. The age of the patients with pneumonia ranging from early adulthood to elderly. Most complication occurred was hypoalbuminemia and most burn area was in the category of $11-20 \%$.

\section{CONFLICT OF INTEREST}

The author stated there is no conflict of interest in this study.

\section{REFERENCES}

1. Toussaint J, Singer A. The Evaluation and Management of Thermal Injuries: 2014 Update. Clin Exp Emerg Med 2014; 1: 8-18.

2. Gupta K, Mehrotra M, Kumar P, Gogia A, Prasad A, Fisher J. Smoke Inhalation Injury:
Etiopathogenesis, Diagnosis, and Management. Indian J Crit Care Med 2018; 22: 180-188.

3. D'Avignon L, Hogan B, Murray C, Loo F, Hospenthal D, Cancio L, Kim S, Renz E, Barillo D, Holcomb J, Wade C, Wolf S. Contribution of Bacterial and Viral Infections to Attributable Mortality in Patients with Severe Burns: an Autopsy Series. Burns 2010; 36: 773-779.

4. World Health Organization. Burns. World Health Organization, https://www.who.int/news-room/factsheets/detail/burns (2018).

5. American Burn Association. Burn Incidence Fact Sheet. American Burn Association, https://ameriburn.org/who-we-are/media/burnincidence-fact-sheet/ (2016).

6. Martina N, Wardhana A. Mortality Analysis of Adult Burn Patients. Universitas Kristen Indonesia, 2013.

7. Dahlan Z. Pneumonia: Buku Ajar Ilmu Penyakit Dalam. Jakarta: Fakultas Kedokteran Universitas Indonesia, 2014.

8. Lim L, Woo Y, de Bruyne J, Nathan a, Kee S, Chan Y, Chiam C, Eg K, Thavagnanam S, Sam I. Epidemiology, Clinical Presentation and Respiratory Sequelae of Adenovirus Pneumonia in Children in Kuala Lumpur, Malaysia. PLoS One 2018; 13: e0209720.

9. Kementerian Kesehatan Republik Indonesia. Riset Kesehatan Dasar 2013. Kemenkes.

10. Perhimpunan Dokter Paru Indonesia. Pedoman Diagnosis dan Penatalaksanaan di Indonesia. Jakarta, 2014.

11. Liodaki E, Kalousis K, Mauss K. Epidemiology of Pneumonia in a Burn Care Unit: The Influence of Inhalation Trauma on Pneumonia and of Pneumonia on Burn Mortality. Ann Burn Fire Disasters 2015; 28: 128-133.

12. Agbenorku $\mathrm{P}$, Agbenorku $\mathrm{M}$, Bayuo J, Asare $\mathrm{N}$. Epidemiology and Outcome of Suspected Inhalational Burn Injury in a Ghanaian Tertiary Hospital. Burn Open 2019; 3: 45-50.

13. Soeselo D, Suparman E. Adequate Fluid Resuscitation Decreases Incidence of Acute Renal Failure in Burn Patients. Universa Med 2019; 38: 108-113.

14. Soeters $P$, Wolfe R, Shenkin A. Hypoalbuminemia: Pathogenesis and Clinical Significance. J Parenter Enter Nutr 2018; 43: 181-193.

15. Damayanti N, Abidin A, Keliat E. The Correlation between Albumin Levels with 30 days Mortality in Community Acquired Pneumonia Patients. OP Conf Ser Earth Environ Sci 2018; 125: 012141. 